änderung auf das Endresultat keinen EinHuss üben, da das gebildete Harz in Äther löslich ist und mit dem Extract gewogen wird; bei Anwesenheit von spanischer Erde werden aber die harzigen Producte von derselben zurückgehalten. Die letzteren Bestimmungen habe ich nur an einer geringeren Anzahl von Futtermitteln, Baumwollsaatmehl, Leinmehl, Erdnussmehl und Rübkuchen ausgeführt, doch werden sich die übrigen vermuthlich ebenso verhalten.

Als Resultat obiger Arbeit ergibt sich, dass bei der Extraction von Futtermitteln durch Anwendung von Gyps und Knochenkohle ein reineres Fett erzielt wird, aber nicht übereinstimmende Resultate sich zeigen. Durch Anwendung von spanischer Erde gelingt es gleichfalls, einen sehr reinen Extract zu erhalten, und die Resultate stimmen stets überein, wenn eine Sorte Äther angewendet wird. Wasserfreier Äther liefert im Gegensatz zu wasserhaltigem Äther niedrigere, aber jedenfalls die richtigeren Zahlen. Ein Vortrocknen der Substanz ist unzulässig und gibt ein zu geringes Resultat.

\section{Über das Färben von Quarzsand mit Azofarbstoffen.}

$$
\text { Von }
$$

\section{Richard Möhlau.}

Für wissenschaftliche Versuche auf wasserbautechnischem Gebiete war die Beschaffung auffallend verschiedenfarbigen Quarzsandes erwünscht. An die Dauerhaftigkeit der Färbung waren die Bedingungen einer gewissen Widerstandsfähigkeit gegen Wasser und einer gewissen Reibechtheit geknüpft.

Da der Quarz weder zu unorganischen noch zu organischen Farbstoffen Affinität besitzt, so schien die Anwendung derjenigen Methoden, welche zur Färbung der Textilfasern zu führen pllegen, hier aussichtslos $\mathrm{zu}$ sein.

Als jedoch eine sorgfältige mikroskopische Betrachtung das Vorhandensein höchst feiner Rillen und Höhlungen in den einzelnen Quarzkörnern ergab, durfte man an die Möglichkeit denken, dadurch zum Ziel zu gelangen, dass man unorganische, farbige Körper, wie Chromgelb, Berlinerblau u. dgl. in den erwähnten Vertiefungen niederzuschlagen versuchte.
Wenn derartige Versuche sämmtlich ein negatives Resultat zur Folge hatten, so liegt der Grund wohl darin, dass die Grösse der einzelnen Partikeln der theils krystallinischen, theils amorphen Niederschläge im Missverhältniss zur Feinheit der Rillen und Höhlungen stand.

Mit gutem Erfolge konnten dagegen die wasserunlöslichen Naphtolazofarbst offe fixirt werden. Das mikroskopische Bild des so gefärbten Sandes zeigte bei 600 facher Vergrösserung die Farbstoffe ganz gleichmässig und in ibren einzelnen Theilchen nicht erkennbar in den Vertiefungen der Quarzkörner abgelagert.

Zur Schilderung des Verfahrens diene die Färbung von Quarzsand mit dem röthlichorangen Benzol-azo- $\beta$-naphtol.

In einem geräumigen, eisernen, mit Rührwerk versehenen Kessel werden $1 \mathrm{k}$ gepulvertes $\beta$-Naphtol mit etwas mebr als der äquivalenten Menge Ätznatron in $25 l$ Wasser gelöst. In diese Lösung werden allmählich $100 \mathrm{k}$ Quarzsand eingerührt. Hat sich derselbe mit der Lösung vollständig benetzt, so lässt man nunmehr in feinem Strahl und unter fortgesetztem Rühren eine Lösung von Diazobenzolchlorid zufliessen, welche vorher durch Vereinigung einer Lösung von $900 \mathrm{~g}$ salzsaurem Anilin und $800 \mathrm{~g}$ Salzsäure von $21^{\circ} \mathrm{B}$. in $3 l$ Wasser mit einer Lösung von $500 \mathrm{~g}$ Natriumnitrit in $2 l$ Wasser bereitet worden ist.

Nachdem die Farbstoffbildung vollendet ist, wäscht man im selbigen Apparat mit fliessendem Wasser aus, bis der Ablauf farblos erscheint und trocknet den nun farbigen Sand.

Da die in Frage kommenden Azofarbstoffe durch Combination des $\alpha$ - und $\beta$-Naphtols mit den Diazoabkömmlingen der verschiedenen primären aromatischen Amine entstehen und diese Combinationen zu sehr verschiedenfarbigen Körpern führen, so hängt es einerseits von der Wabl des Naphtols, andererseits von derjenigen des zu diazotirenden Amins ab, welche Färbung man dem Quarzsande ertheilen will.

Laboratorium für Farbenchemie und Färbereitechnik, Technische Hocbschule Dresden. 